\title{
PREPRINT
}

Martín-Pastor, Andrés \& García Alvarado, Rodrigo. Developable wooden surfaces for lightweight architecture. Bio-Dune Pavilion. In: Bianconi, Fabio, Filippucci, Marco (Eds) DWD. Innovative techniques of representation in architectural design. Lecture Notes in Civil Engineering. Vol. 24. Springer, 2019. Pp. 1481-1500. ISBN: 978-3-030-03675-1. Doi: https://doi.org/10.1007/978-3-030-03676-8_60

\section{DEVELOPABLE WOODEN SURFACES FOR LIGHTWEIGHT ARCHITECTURE. Bio-Dune Pavilion}

\author{
Andrés Martín-Pastor*, and Rodrigo García-Alvarado
}

* Correspondence: ETSIE, Dept. Graphic Engineering, Universidad de Sevilla, archiamp@us.es

\begin{abstract}
:
Within the broad context of teaching and research, the results of a project involving a pavilion based on developable wooden surfaces, parametric design, and digital fabrication are presented through the collaboration of Ibero-American universities. The project addresses applications of wood to architecture that involves the CNC cutting of plates, thanks to the properties of developable surfaces. The in-depth knowledge of the geometrical properties of these surfaces opens up a wide range of morphological exploration and new constructive solutions. The proposed system provides a creative response to the criteria of limited material resources (a thin sheet of material) and low production and assembly costs as an analogy with natural construction. This high-tech and low-cost system, together with the Bio-mimetic design, offers an ecocompatible proposal to the three processes under study: design, manufacture, and assembly.
\end{abstract}

Keywords: Wood design, flexible wood, developable surfaces, wood complex surface, parametric design, digital fabrication, pavilion, woodworking

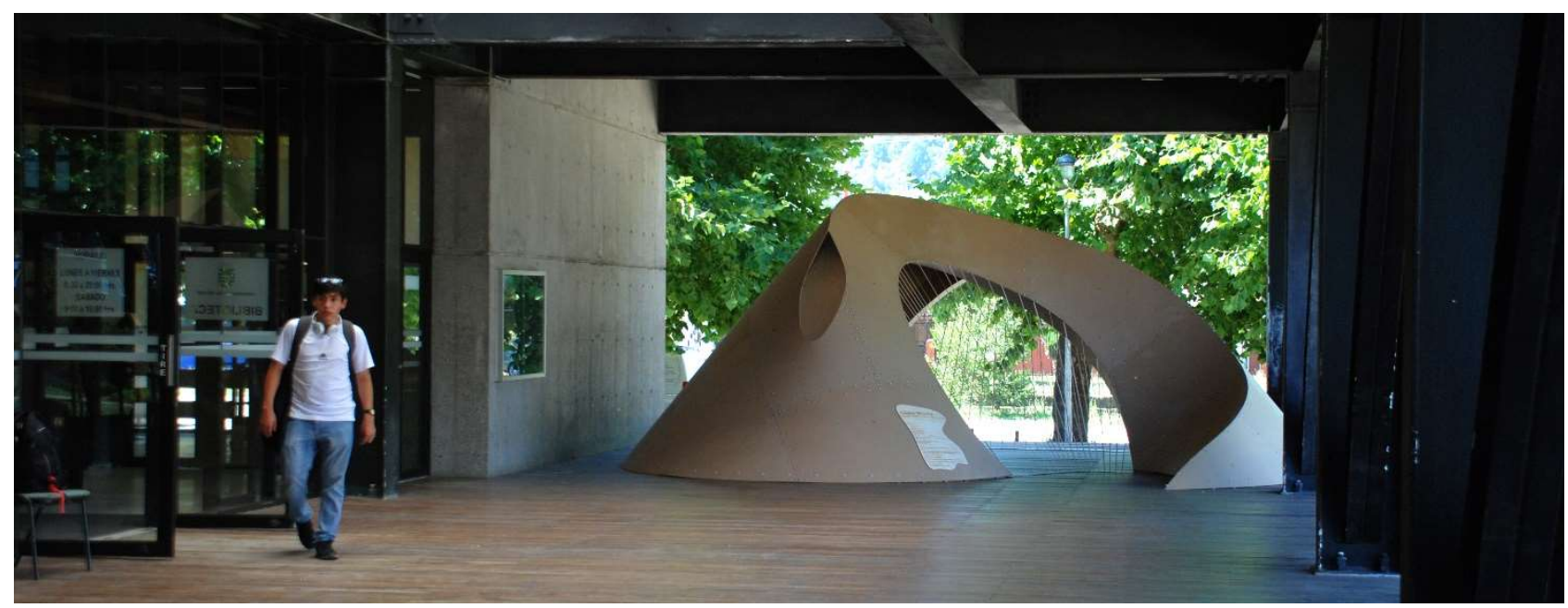

Fig.1: Bio-Dune Pavilion. Hilario Hernández Gurruchaga Library, Bío-Bío University, Concepción, Chile, January 2017 


\section{Introduction}

The project forms part of an open line of research on the geometry of developable surfaces and its application in architecture. These collaborative experiences have been developed among Ibero-American universities, in intensive conferences on teaching and research. The general proposal consists of approaching the phases of design, digital fabrication, and assembly of a wooden pavilion by means of Descriptive Geometry and with digital tools. A low-cost and reusable construction is proposed that is designed to be cut in a digital fabrication workshop while armed with a simple instruction manual. The academic project is articulated in a workshop format by applying a theoretical-experimental model that is verified through the realization of smallscale prototypes and, finally, with the assembly of the full-scale architectural installation.

The experience carried out in Chile (Fig.1) is that of a hollow dune, called the Bio-Dune Pavilion, consisting of a self-supporting skin of MDF (Medium Density Fibreboard) of $5 \mathrm{~mm}$ thickness. This ephemeral installation was mounted in the access gallery of (Authors' references eliminated). The pavilion was created through a workshop within the framework of the... (Authors' references eliminated).

The proposed design, fabrication and assembly system strives to provide an optimized architectural response to the requirement for minimum material resources and reduced production costs. This design is unlike other international experiences that have applied similar strategies and equipment, but with rigid pieces and/or using additional supports (Jabi, and Woodbury 2013). Digital architecture in wood is proposed that is based on the geometric properties of developable surfaces, and on enabling a favourable strength-to-weight ratio of the wood pieces themselves, plus the power of digital tools and digital fabrication laboratories.

\section{Contextualization. Previous Experiences}

The facilities designed and built in this research strategy are based on the geometrical properties of thin wooden sheets and their ability to be bent while cold from a flat initial state. Through the use of CAD/CAM tools, parametric generation laws have been defined that enable different types of developable surfaces to be handled and, subsequently, their deployment in smaller flat pieces. These pieces have been digitally cut by a numerically controlled CNC milling machine, and then manually assembled as a large puzzle on the ground. Each of the proposed prototypes is a self-supporting skin made up of a single layer of material of a thickness ranging between 3 and $6 \mathrm{~mm}$, where final stability depends on the geometry and folding.

The experimental journey began with the 'quadrilateral intersection theorems' put into practice with the installation 'The Caterpillar Gallery' (Fig. 2a) (Authors' references eliminated) (Narváez-Rodríguez et al 2014), and 'The Cocoon' (Fig. 2b) (Authors' references eliminated) (Martín-Pastor et al 2014). We have also addressed the study of developable surfaces of equal slope, with the pavilion 'SSFS Pavilion - Sante Fe' (Fig. 2c), in (Authors' references eliminated) (Chiarella, and Martín-Pastor 2015). An improved and complete adaptation of the same design was produced with (Fig. 2e) (Authors' references eliminated).

The developable helicoidal surfaces of a cylindrical helix were subjected to formal exploration with the 'Butterfly Gallery - Helicoidal Surfaces' (Fig. 2d) (Authors' references eliminated) (Martín-Pastor 2015). This same type of helicoidal surface was also the geometrical argument of the bio-mimetic installation titled 'Mollusc Pavilion' (Fig. 2f), inspired by the form of Bolinus Brandaris, made at (Authors' references eliminated). The expansible properties of these helicoidal surfaces were developed in depth in (Authors' references eliminated) (Martín-Pastor and López-Martínez 2017). After the 'Bio-Dune Pavilion', the resulting surface of tangentially convoluted linking with the installation 'Dieste-Pavilion' (Fig. 2g) was explored at (Authors' references eliminated).

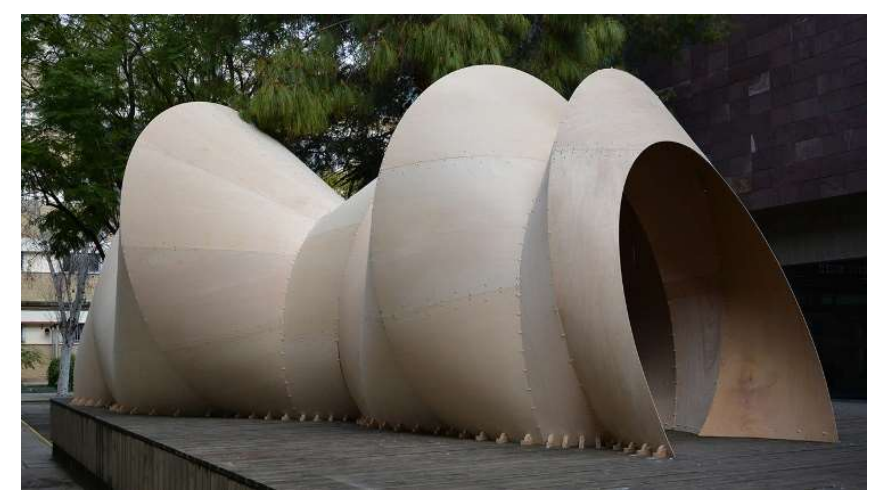

Fig. $2 a$ 


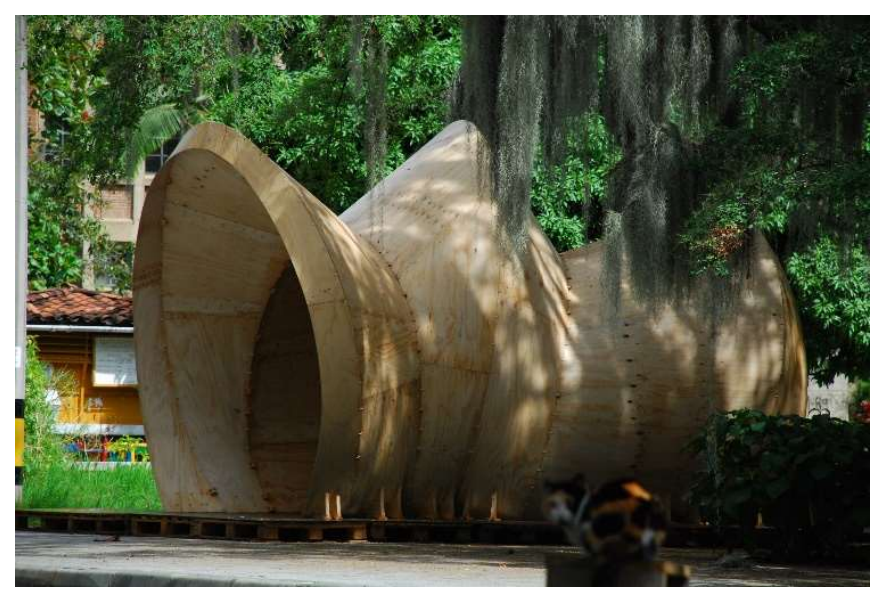

Fig. $2 b$

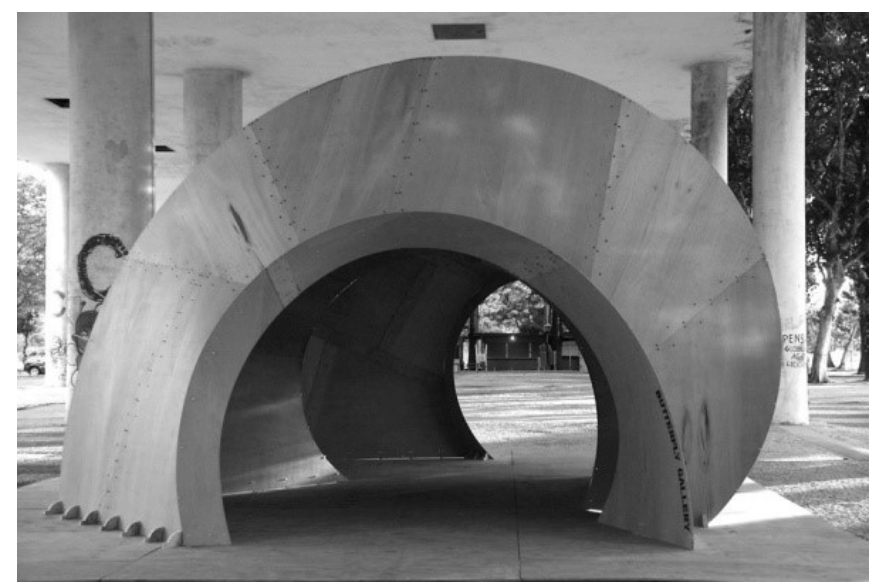

Fig. 2d

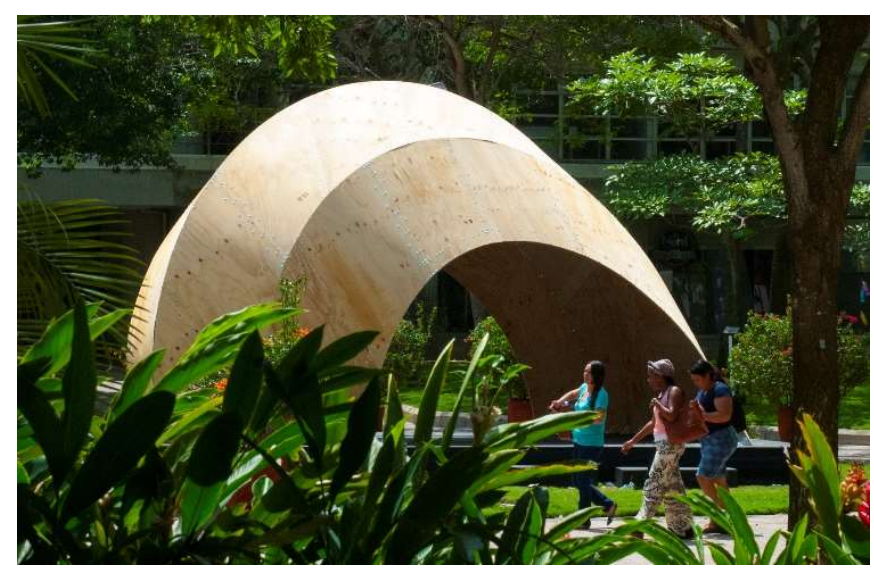

Fig. $2 f$

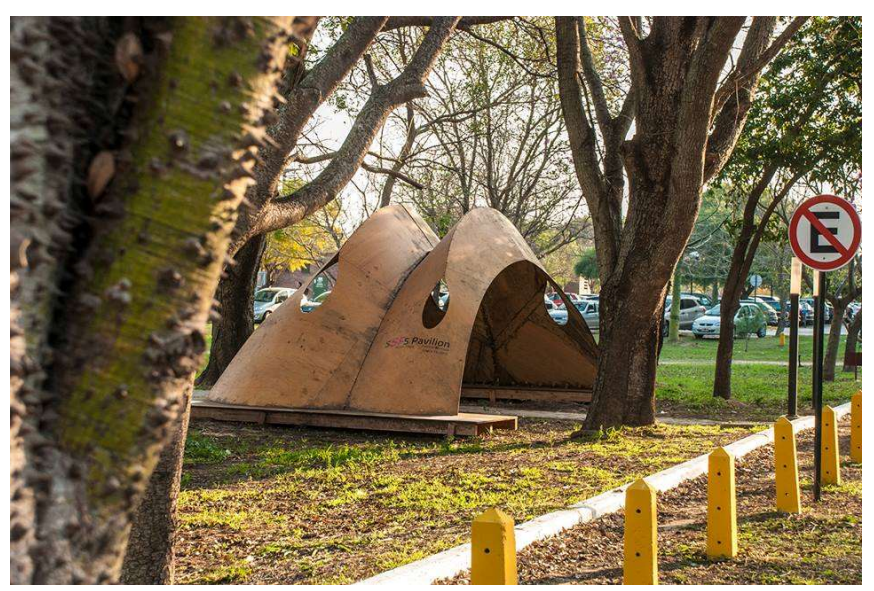

Fig. 2c

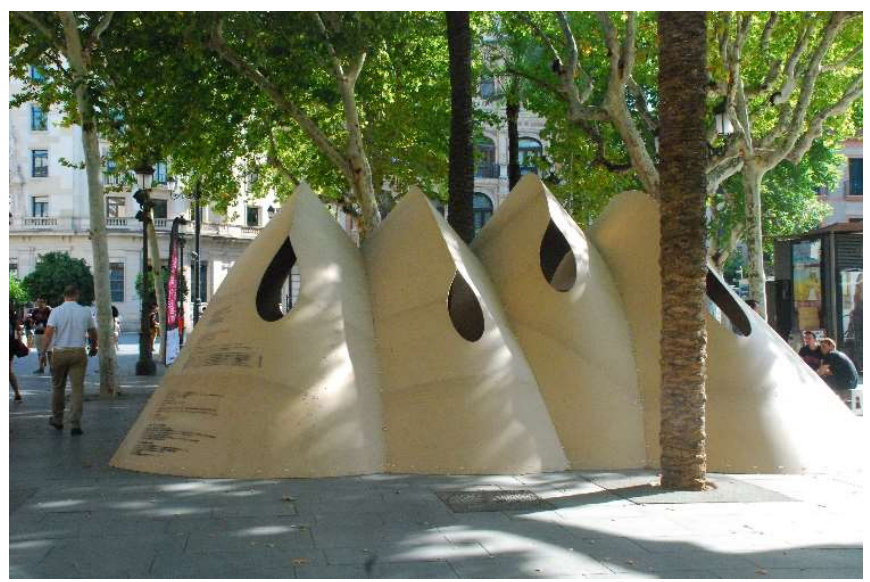

Fig. 2e

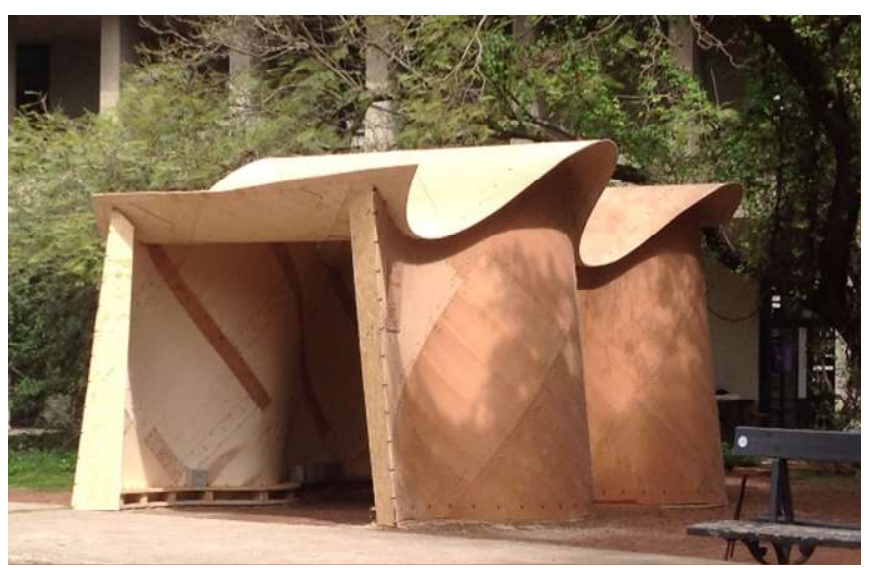

Fig. $2 g$

Fig.2a: Caterpillar Gallery, Seville 2014; Fig.2b: Cocoon Gallery, Medellin 2014; Fig.2c: SSFS Pavilion Santa Fe, 2015; Fig.2d: Butterfly Gallery, Rio de Janeiro 2015; Fig.2e: SSFS Pavilion - Fablab Sevilla, 2015; Fig.2f: Molusco-Pavilion, Barranquilla 2016; Fig. 2g: Dieste-Pavilion, Montevideo 2017 


\section{Lightweight architecture in wood as a digital fabrication process}

\section{STAGE PD-DP ( parametric design \& digital production)}

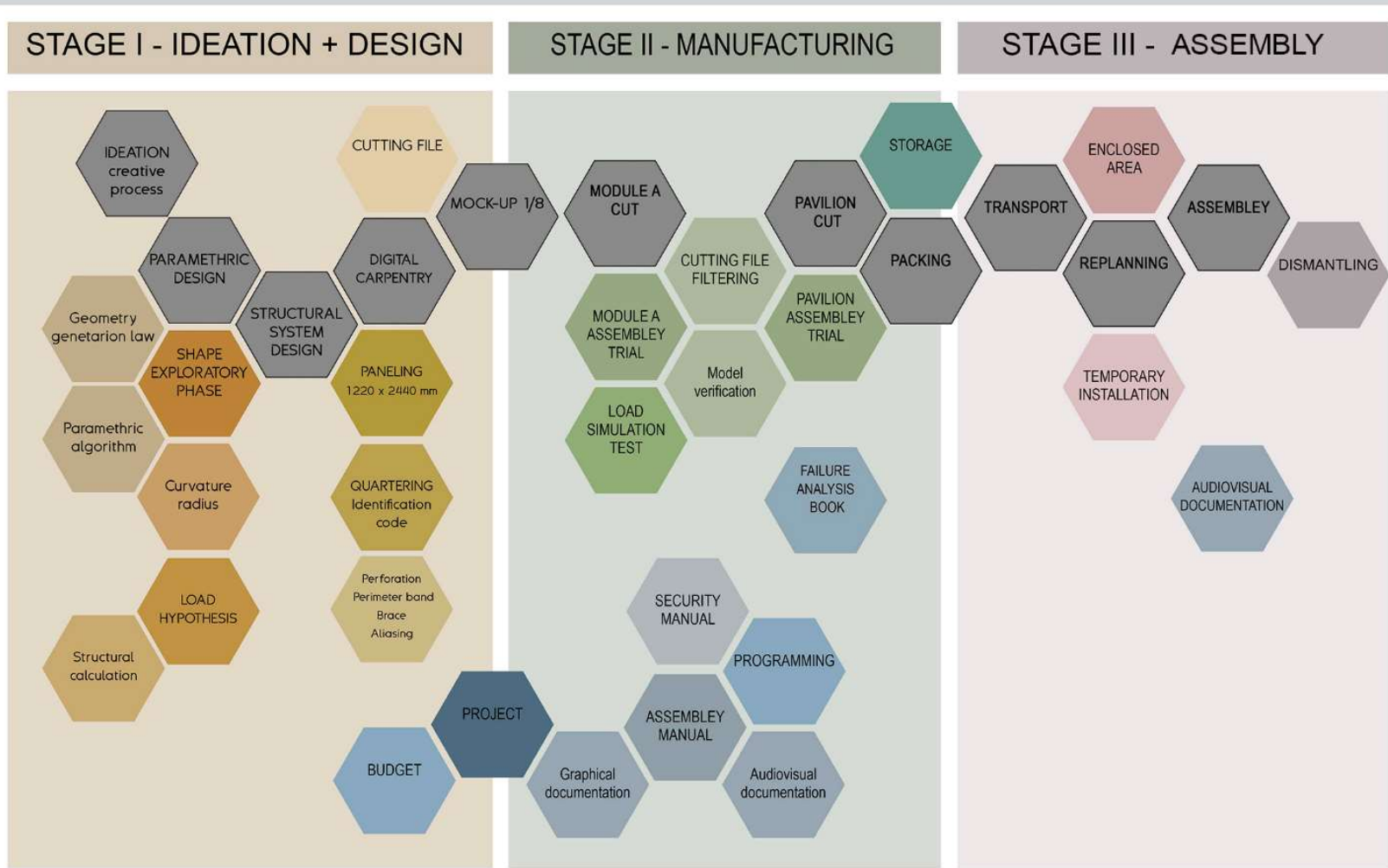

Fig. 3. This diagram summarizes the three main phases of the process: Design, Manufacture, and Assembly, showing the lines of feedback that occur between said phases (Source: Authors' own)

Logic similar to that used in the furniture industry has been followed: create an optimized and efficient design, and a decentralized production that minimizes materials the cutting process and transport, and then designate the final assembly of the product to the user. Three main phases have been differentiated in the process: Design, Fabrication, and Assembly (Fig. 3). Each of these phases is sufficiently autonomous to be carried out by different people. As in the furniture industry, the key is in optimizing resources, energy, and labour, which ultimately have repercussions on the cost of the architectonic work.

The process includes these three phases in addition to tests, analyses and feedback carried out until a final product is attained. In this project, we consider the 'design phase' to be that which ends with the creation of the CNC cutting files to produce the full-scale prototype. This phase includes the conception (Meredith 2008), the generation of the parametric algorithm, the exploration of the form, the development of the constructive design, the structural calculation, the flat development of the surface, the cutting of said piece, the estimation of the cost (human resources, materials, and time factors), and finally the preparation of the cutting files (Oxman, and Oxman 2014).

The project is verified by means of the creation of a small-scale model (scale 1:8), where the possible errors in the cutting are checked, as well as the feasibility of the assembly sequence (Sass, and Oxman 2006). The fabrication phase in the digital manufacturing laboratory is then started, which not only comprises the cutting of the contour of each piece, but also the machining for the passage of all the bolts and connecting elements, as well as the engravings (alphanumeric code writing) that guarantee the correct positioning of the pieces. This phase contemplates the refinement of the cutting files and the optimization and planning of work within the workshop, where strict security measures are required. Likewise, the way of packaging, storing, and transporting said pieces to the place of assembly is anticipated.

The assembly phase requires a small number of generally non-specialized personnel for the assembly process whose protocol must be included in an annexed document that forms part of the project. The creation of this manual with graphic and precise instructions for assembly forms part of the digital manufacturing process. In this case, it is the design team who are responsible for producing the instructions of said assembly manual, which should allow the raising of the pavilion without any margin of error and for any work team (Fig.4). 
At the same time, safety measures are contemplated in the work and ergonomic recommendations in these tasks.

Bringing ideas from the field of industrial furniture to the world of architecture carries advantages from the point of view of sustainability. The concept of digital craftsmanship emphasizes the figure of the architect, or designer, as holding the maximum responsibility for the interaction of all digital processes related to design and production. The classic model of the construction process is altered, where the architect is the author of two-dimensional graphic information and a group of specialized craftsmen/craftswomen/builders execute, with more or less expertise, that which has been previously defined in the project. Kohler and Gramazio (2008) place digital materiality among the complex interweaving of computer programming, 3D construction (or digital modelling), data and matter, in the various stages of the architectonic project.

In the manufacturing process, the robotic cutting machine (CNC) is responsible for the fabrication and machining of the work. Human error is considerably reduced, whereby humans focus on only the supervision and optimization of processes (Iwamoto 2009). All aspects of the architecture are reduced to a set of elements where there is no shortage or surplus of any piece of wood or any metal fixing element. In this way, only that necessary is produced, thereby minimizing the waste generated in the manufacturing process. Likewise, the process of packaging the material guarantees that only the material that is truly necessary is transferred to the assembly site, since this is a type of joinery construction that generates no waste (Martín-Pastor et al 2017a).

\section{DUNE PAVILION}

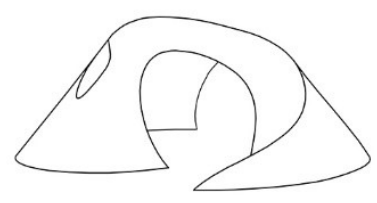

2

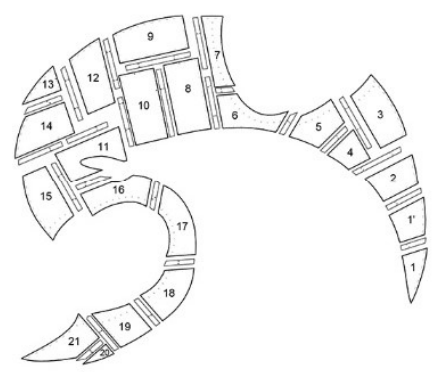

6

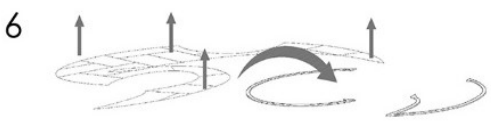

7

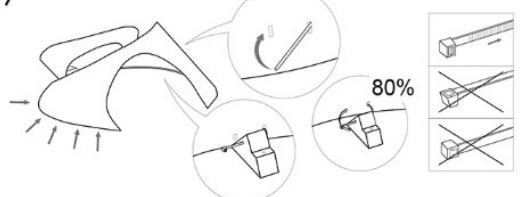

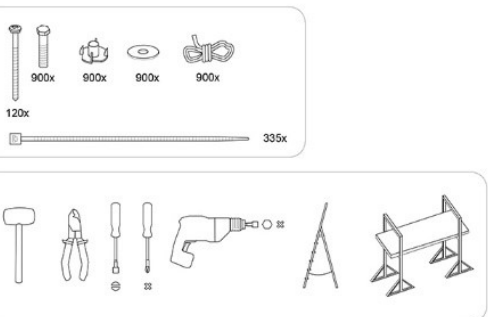

3

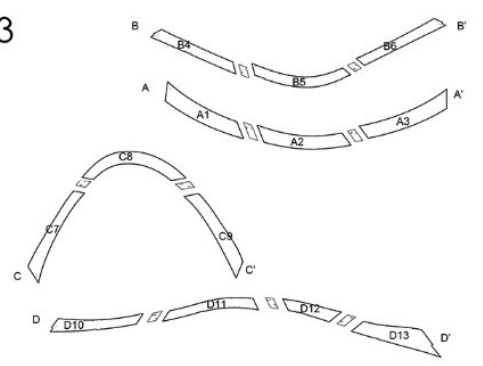

8

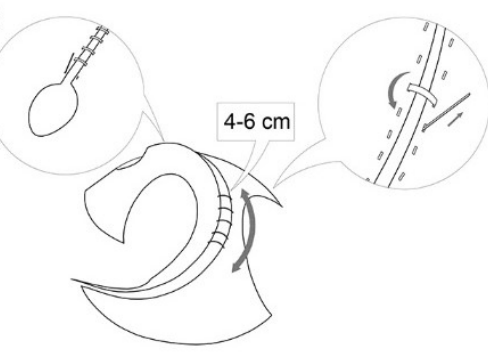

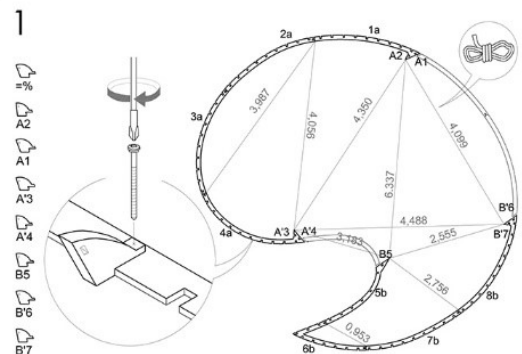

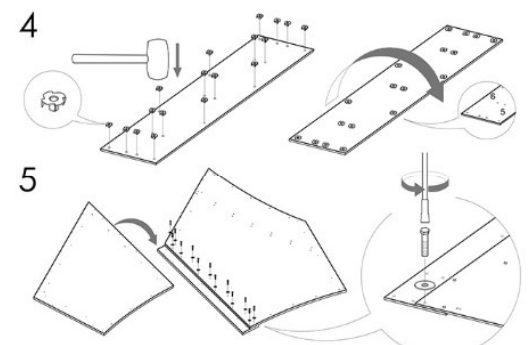

9

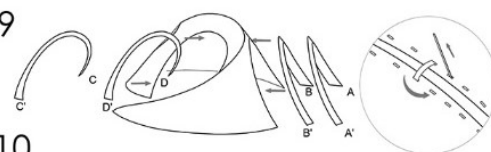

10

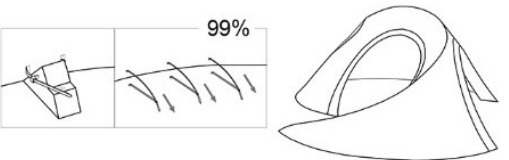

Fig. 4. Assembly manual of the Bio-Dune Pavilion. (Source: Authors' own)

\section{Geometry in the post-digital era, digital fabrication and construction in wood}

Approaching a project of this nature requires a triple study; one must address the 'fundamentals of geometry', the 'fundamentals of software', and the 'fundamentals of digital fabrication'. The network of knowledge, skills and abilities of students needs to grow in complexity, by assuming conceptual competences (theory and fundamentals), instrumental competences (design tools), and productive competences (manufacturing tools) (Celani 2012). 
The 'fundamentals of geometry' provide the grammar that enables the operation of higher geometric reasoning which serves in the articulation of problems and specific solutions in architecture. Without entering into debate on the current importance of Descriptive Geometry (Tafteberg Jakobsen, and Matthiasen 2014), this discipline has been especially prolific in treatises, and the purpose of its teaching has been to put these skills into practice. The field of traditional woodwork (structural carpentry) as well as other crafts, such as stonework, plastering, and tiling, is a common territory where this knowledge can be put into practice. These geometric foundations as the basis of digital design in wood and digital manufacturing are therefore not unusual nor innovative.

Five phases of the architectonic process have been synthesized where knowledge of geometry is strongly present.

'Geometry and creativity'. The geometric idea of the project. In the tradition of architectonic drawing, it could be related to sketching. In parametric design, we talk about the form-generating algorithm.

'Geometry, graphic definition, and control of the form'. The drawing of the creation, or the 3D model as a substitute for the object, which could be related to the definition that a basic project demands.

'Geometry of precision and of details'. The geometric definition of each of the parts of an architectonic object and the relations of conjunction or assembly of the parts with each other. It is a level of precision necessary for the creation of the cutting file.

'Geometry, measurements, and economic cost'. Geometry as a measurement tool.

'Geometry, construction, and assembly'. This is the geometry necessary in the graphic definition of the assembly systems, which explains the assembly processes and the geometry of the control systems.

The five phases discussed above, in relation to the basic processes of digital fabrication, principally coincide with the 'design', manufacture', and 'assembly' of industrialized production. Each of these processes can be conceived in autonomous actions, while maintaining close similarity with the processes of planning and industrial production.

The experience of design, manufacture, and assembly of a pavilion from the geometric foundations also becomes an exercise of intergroup communication and coordination, whereby students can work on the necessary skills of teamwork (Fig. 5). Likewise, the final scenario of the assembly and display of the installation is also revealed as fundamental in carrying out these relations and optimizing the programming of the assembly (Alvarado et al 2009).

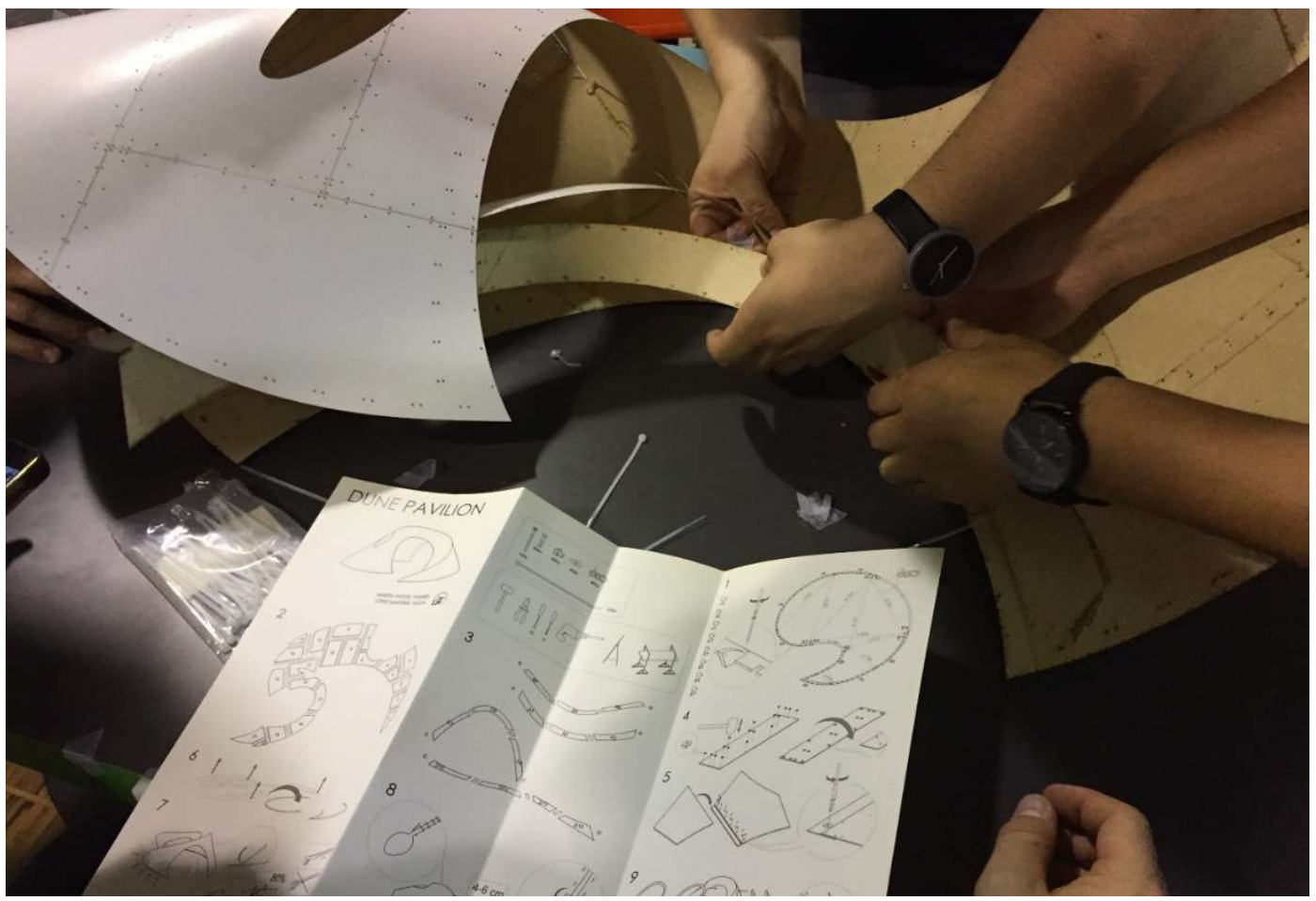

Fig. 5. Assembly of the model reduced to a scale of 1:8, and where to check for possible errors and to optimize processes (Source: Authors' own) 
Another major aspect incorporated into this working formula should be borne in mind: the digital tool is conceived as a laboratory of geometric research where, empirically, the geometric and structural properties of the surfaces to be put into practice are investigated. In this way, a variable that transcends that of purely teaching is added to the initial approach to convert the experience into an experimental research workshop (Casale A et al 2013).

\section{Dunes as a source of inspiration. Bio-mimesis, morphogenesis, and the project}

Dunes are dynamic elements of topography and include a natural adaptation of the terrain to climatic variations with minimal surfaces. The incorporation of bio-mimetic or morphogenetic logic with respect to formal search techniques constitutes a field of exploration that has been addressed by numerous researchers over the last decade (Hense et al 2010), (Weinstock 2010). The shape of a dune in its natural state is defined by various parameters: the angle of internal friction of the granular material that forms it, the prevailing winds of the area, the natural obstacles, the presence of vegetation, humidity, the pockets of material in its lowest area, etc. However, from an ideal point of view, any dune is, geometrically, a surface of equal slope defined by the natural angle of the terrain that forms it (Fig. 6). A dune is always a developable surface in that it can be unfolded on a plane without pleats, bulges or folds, and this provides enormous constructive advantages. The dune could therefore be understood as a hollow structure formed by a thin sheet of material that works in its entirety as a self-supporting skin.

Under the assumption of this law of generation of a dune, the composition of the project can be determined by a very precise geometric and mathematical logic. This exerts consequences on the level of pure design, since this parameterized architecture offers strong tension between the formal creation and the margin of freedom of the generation law chosen. The formal, constructive, and structural solutions are articulated within the infinite variants and/or mutations that the initial genetic code allows, which is assumed as part of the project (Whitehead 2005).

The morphological research and the study of the material possibilities of the project are therefore strongly linked to the tools, which in this case constitute the parameterization software. The designer makes use of these tools by exploring their possibilities, anticipating the final result without the modifications of their parameters dissociating the relationships of the parts from each other, and by maintaining the integrity towards its final manufacture (Ramsgard Thomsen, and Tamke 2013).

Therefore, and paradoxically, the artisanal quality of the process, 'digital craft', will tend to be increasingly present in the initial phases of design, and necessarily tend to disappear in the final processes, since the ultimate goal is the automation of all reiterative actions, including those of Self-Detailing and Self-Documenting Systems (Meredith, and Kotronis 2013). A previously analysed concept, called "constructed digital materiality", is thereby connected (Chiarella et al 2018).

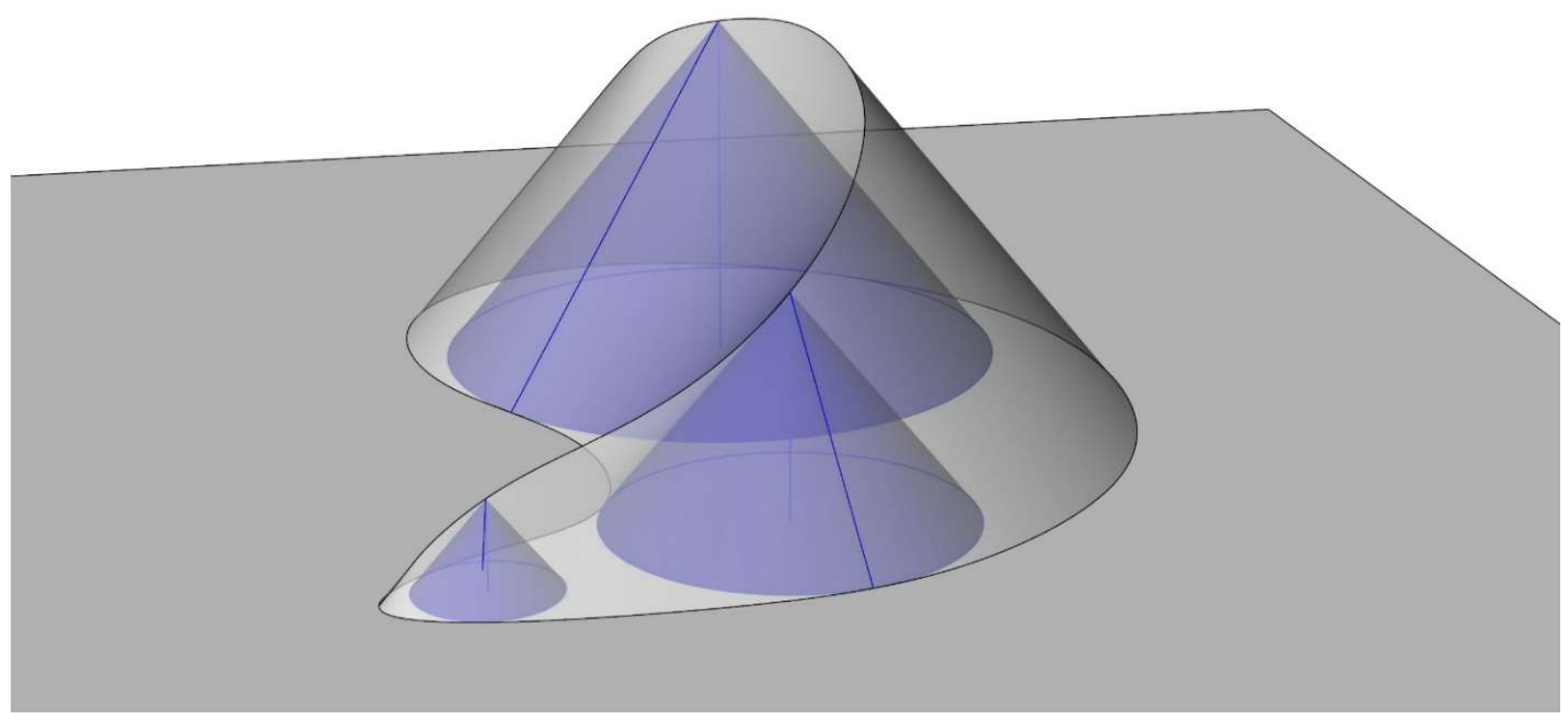

Fig. 6. The dune is generated as the enveloping surface of a series of cones of the same slope (Source: Authors' own) 


\subsection{Developable surfaces of the same slope. Algorithms of generation of the form}

Developable surfaces are well-known mathematically: they belong to the category of ruled surfaces, as constituted by a set of straight lines arranged according to a type of law, and are usually classified into three groups: cylinders, cones, and tangential surfaces (Glaeser, and Gruber 2007). Their study is strongly marked by the mathematical progress of the eighteenth century and the figure of Gaspard Monge $(1769,1780,1785$, 1795a, 1795b), Jules de la Gournerie (1860-64), among others. The morphological approach has been carried out from graphic thinking, following the conceptual premises of Descriptive Geometry, the potential of digital tools, and parametric design. These surfaces can be studied from two different directions: on the one hand, the approximate processes can be studied in order to convert any type of surface into a discrete series of developable surfaces (González-Quintial et al 2013), (Barrallo et al 2017), or, on the other hand, they can be studied in order to morphologically enter into greater depth into the different ways of generating surfaces that are strictly developable in a continuous way.

The dune is included within the developable surfaces 'of equal slope', this being a specific case of the tangential surfaces. It is not a usual surface in architecture although its generation does appear in certain Descriptive Geometry texts, such as that by Izquierdo Asensi (1985), Gentil Baldrich (1990), and others close to Architectural Geometry (Pottmann 2010), (Glaeser 2012). Despite being a tangential developable surface, its edge of regression (the curve where all the straight lines are supported tangentially, and the one which separates the two leaves from the surface) is not known a priori, unlike the helicoid or other developable surfaces. Therefore, the generation of the surface must be formulated from a different curve on which to impose the angular conditions. Two possibilities of parametrically generating the surface are considered, which correspond to the two ways of its interpretation (Martín-Pastor 2019):

The first consists of conceiving the generation from the bottom up. In this way, a flat directrix guideline is determined, considered as the 'contour of the dune', on which a set of straight lines are supported perpendicularly, which maintain a constant angle $\beta$ with respect to the plane of the directrix. Using this formulation, the crest of the dune, which is a three-dimensional curve, is entirely determined by the twodimensional contour of the guideline and the support angle $\beta$.

The second formulation consists of conceiving the generation of the surface from the crest of the dune downwards. This formulation strives to roughly determine the enveloping surface of the displacement of a cone along the upper curve or crest. The generatrices of the cone, since this is an equiangular surface with respect to a horizontal plane of reference, determine the slope of the surface. With this formulation, the contour of the base of the dune can be determined by means of the three-dimensional geometry of the crest.

The two algorithms that control the shape of the dune from the two conditions presented above (the base and the crest), must be sufficiently debugged and be sufficiently operative for the design. Only then can they become an appropriate tool for the exploration of architectonic form and, consequently, useful for design purposes.

It should be considered that the software used (Rhinoceros-Grasshopper) does not always handle these developable surfaces precisely with their usual "development" commands. Therefore, the developability (ability to move from space to the plane) becomes an algorithmic problem in itself. In order to solve this new problem, a third processing algorithm has been defined.

\subsection{The constructive system}

The construction system of the Bio-Dune Pavilion has been conceived by taking into account the feedback between the phases of design-manufacture, design-assembly, and fabrication-assembly, from previous experiences. In accordance with the objectives, the proposed architecture must have no improvisation in its manufacturing and assembly phases (Hauschild, and Karzel 2011).

Its structure and materiality constitute a self-supporting skin formed, in principle, by any thin laminar element, capable of being curved when cold. The use of wood is supported by its aesthetic and constructive properties, such as lightness, flexibility, ease of cutting and assembly, structural strength of the resulting final assembly and the safe handling and assembly of the pieces, as well as its low cost (compared to other thin laminars such as sheet metal) (Solomon et al 2012). The tensile strength of the fibres of the wood around the fixing points also offers a suitable response.

The assembly process of the pavilion is planned to take place on-site (Fig 7). Once the whole pavilion has been development as a flat surface, it must be broken down into smaller parts, no larger than the dimensions of the panels of the local industry. The dimensions of the MDF panels in Concepción, Chile, were $1200 \times 2440 \mathrm{~mm}$ and the cutting machine was a CNC with a bed of $1300 \times 2500 \mathrm{~mm}$. 
The self-supporting skin of the pavilion rests on a $30 \mathrm{~mm}$-thick base beam that is fixed to the pavement. In this beam, a series of brackets are placed vertically and fixed by screws. The function of these brackets is to fasten the skin along the base-beam, thereby forcing the surface of the dune to rest on said beam, and hence the final shape is acquired (Fig. 8). In turn, the beam absorbs the horizontal stresses of the surface lamina of the dune, which, through active tension, strives to recover its flat shape (Figs. 9 and 10).

In order to guarantee the rigidity of the free edges of the accesses to the pavilion, two curved beams of triangular section were created along the edges. This beam is made by folding the skin of the pavilion inwards twice. As with the skins, the beam was cut with respect to the maximum dimensions established by the local industry.

The geometrical continuity of all the pieces that form the large surface of the pavilion is achieved by bolting a $160 \mathrm{~mm}$-wide overlapping strip behind each cutting line. The bolts are staggered along four lines parallel to the cut. These bolts are separated by a distance of $250-350 \mathrm{~mm}$, which guarantees the mechanical behaviour of the material. This system of connection is created by means of a T-nut, a bolt, and a washer. The perforations for the passage of the bolt and T-nut are made by CNC machining.

The system of fastening the skin of the dune with the beam, and that of fastening the edges of the triangular beam that reinforce the accesses, is carried out by means of nylon flanges. These flanges sew the different skins along the edge of the crest of the dune with the help of mechanized holes, arranged specifically in the design (Fig. 11).

\subsection{Panelization of the final surface and generation of the cutting files}

From a quantitative point of view, the surface that makes up the pavilion is constituted by a series of pieces extracted from standard panels; this leads us to consider several ways of proposing optimization. A first criterion contemplates taking advantage of the maximum amount of material. Another optimization criterion prioritizes the use of the smallest number of machined end pieces for its construction (leaving open the possibility of not taking full advantage of each panel). A third criterion seeks to reduce the number of joining elements (T-nuts and bolts) and the extra material needed for the overlap, as well as the assembly time.

For the minimization of the material resources, the most effective criterion is that which needs the smallest number of panels and the smallest number of overlaps between pieces. However, other factors unrelated to this geometric optimization intervene in the way that the cutting is broken down. In the first place, it is necessary to guarantee the correct mechanical behaviour over time of the structure. To this end, it is important to prevent the orientation of the overlaps from coinciding with the orientation of the straight lines which conform the surfaces, by maintaining an angle preferably close to $45^{\circ}$ between said surfaces. Secondly, it is important to avoid long seam lines that travel across the surface from component to component. To this end, the pieces are staggered. Finally, it is important to reinforce the free edges of the surface, either with edge ribbing, or with reinforcements made specifically for that purpose. It is also necessary to ensure that no hole or machining is located between the seam lines or over a bolt.

A more complete optimization criterion should take into account other issues, apart from the purely quantitative structural criteria and the criterion of material: these include the cutting time, ease of packaging of the pieces, ease of transport, and ease of assembly. The work of cutting is therefore a complex task to automate and remains far from the precise incorporation of each and every one of the parameters that intervene therein into the algorithmic programming (Bohnenberger et al 2011) (Burry 2013). This demonstrates what was previously stated regarding the feedback between the design, manufacturing and assembly processes, in that a constant revision and refinement between phases is crucial for the development of this approach (Mesnil et al 2016) (Austern et al 2018). 


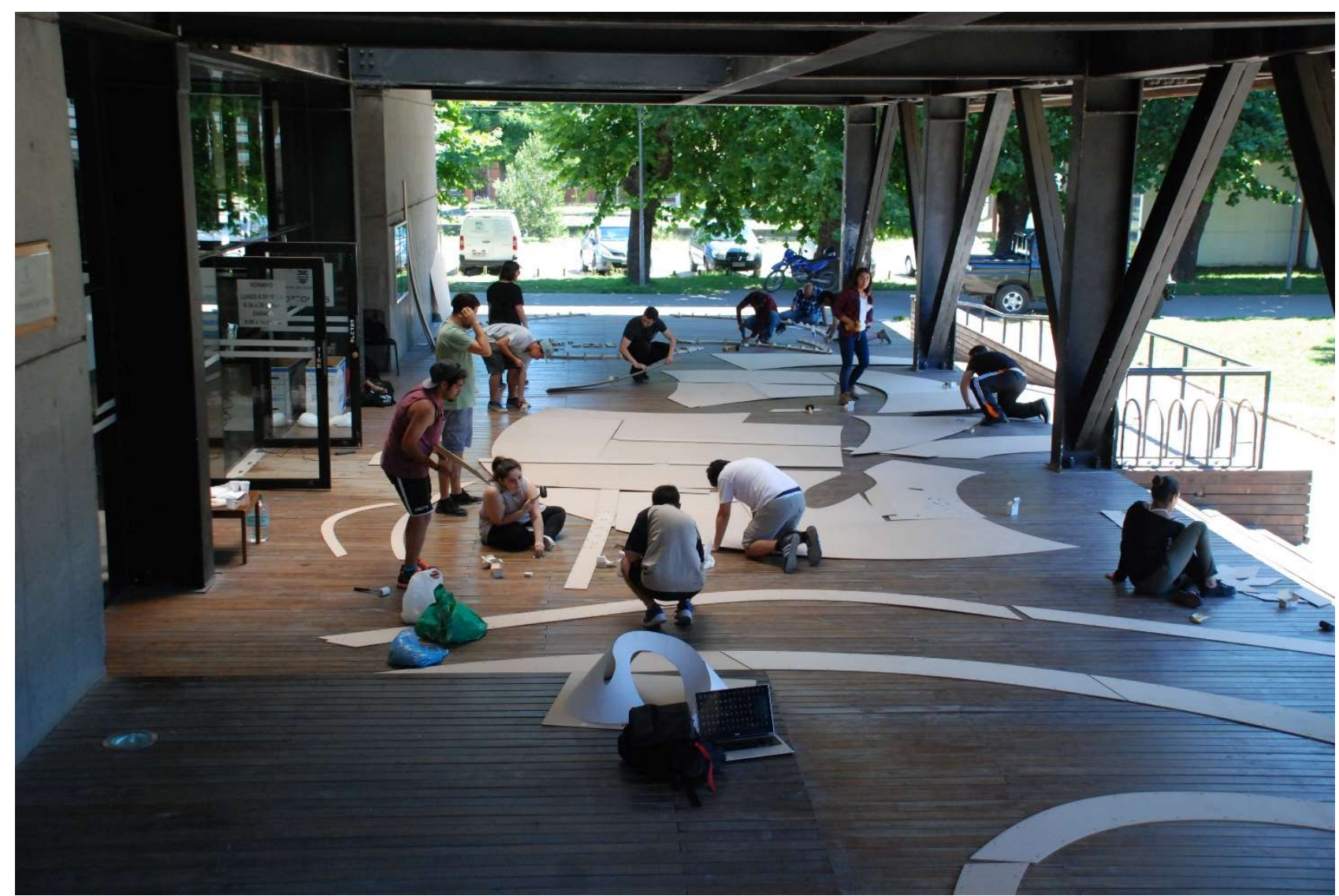

Fig. 7. Reorganization on site. Bio-Dune Pavilion (Source: Authors' own)

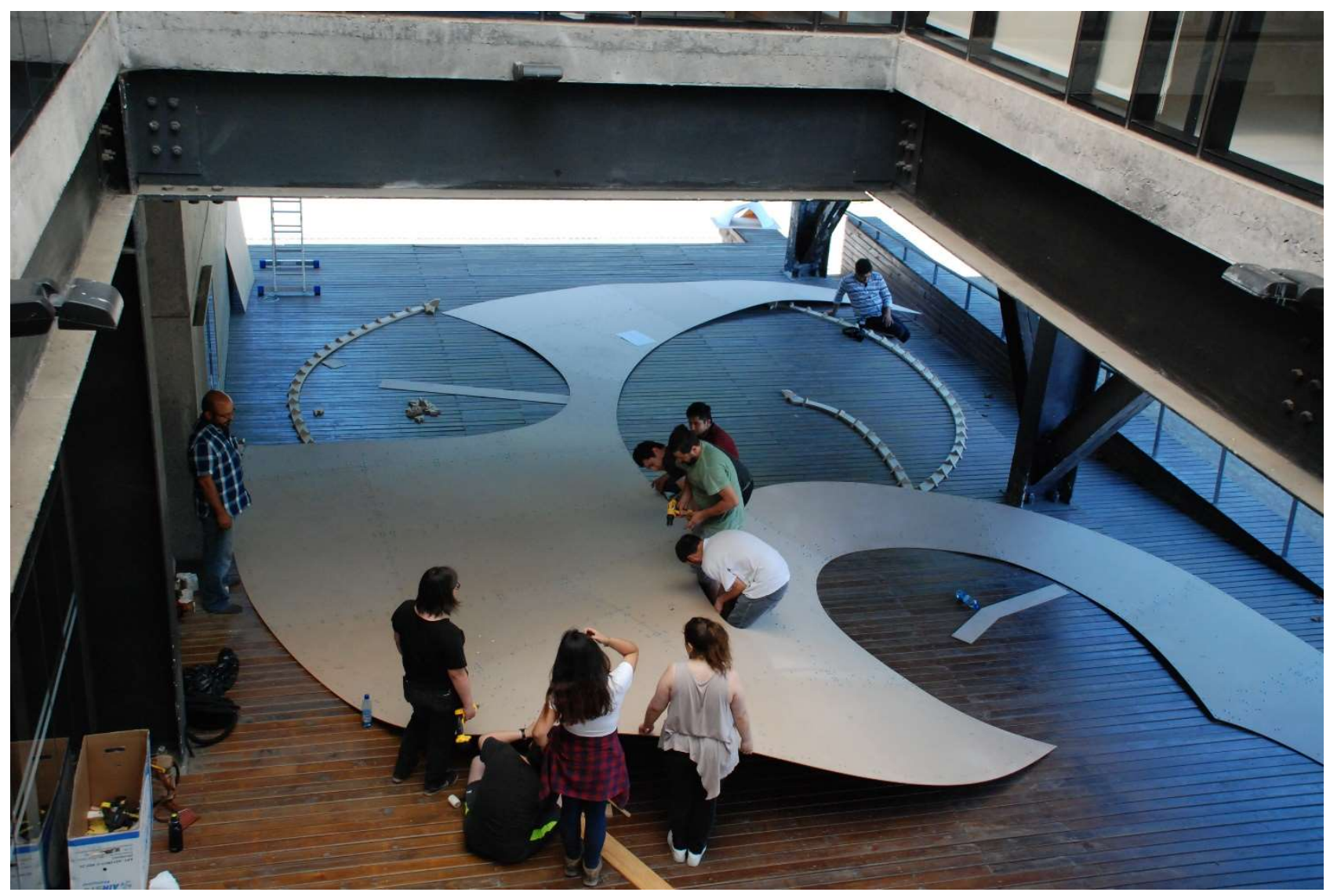

Fig. 8. Assembly of the Bio-Dune Pavilion as a single skin (Source: Authors' own) 


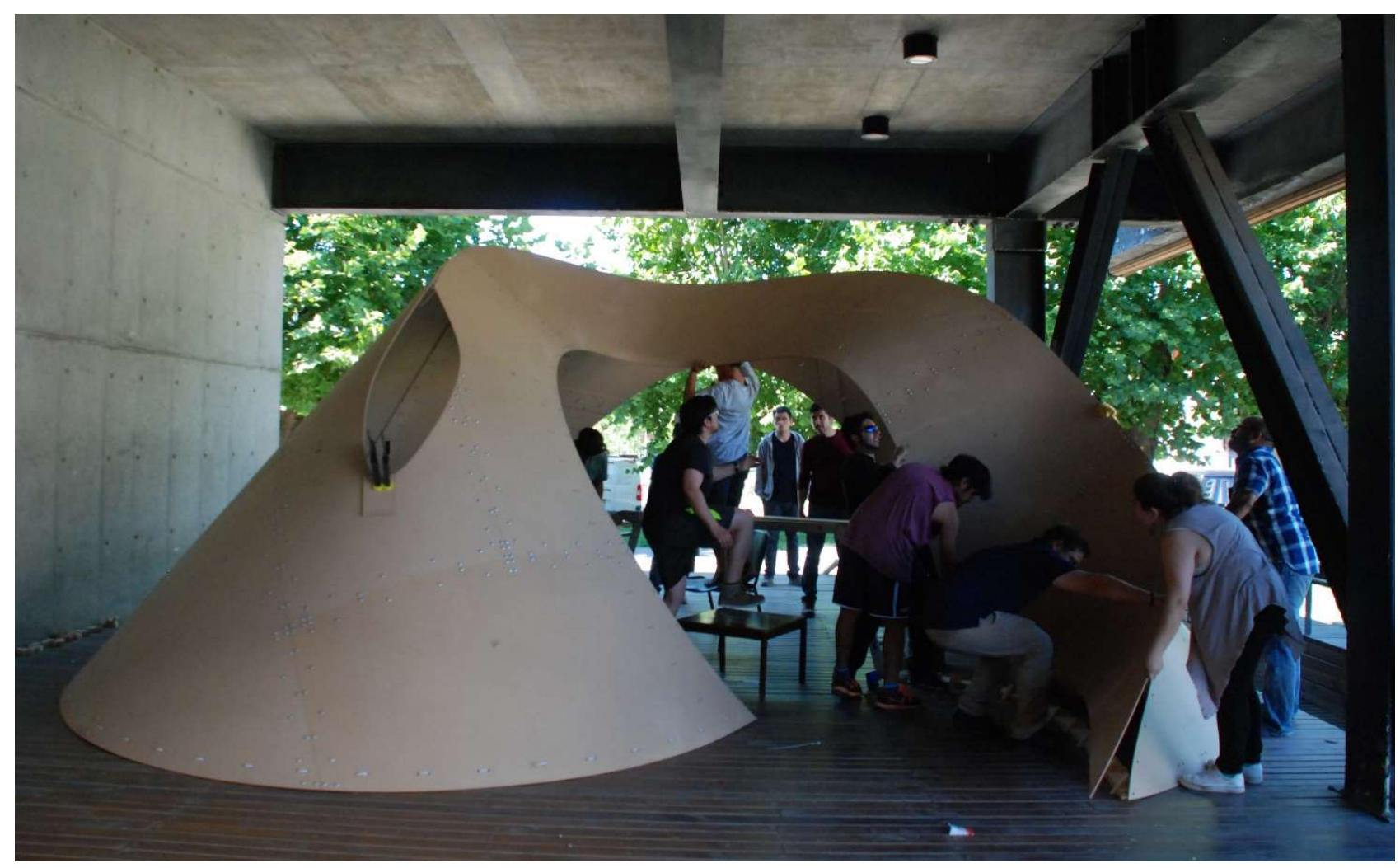

Fig. 9. Curvature and fastening of the skin along the crest of the dune and along the base beam (Source: Authors' own)

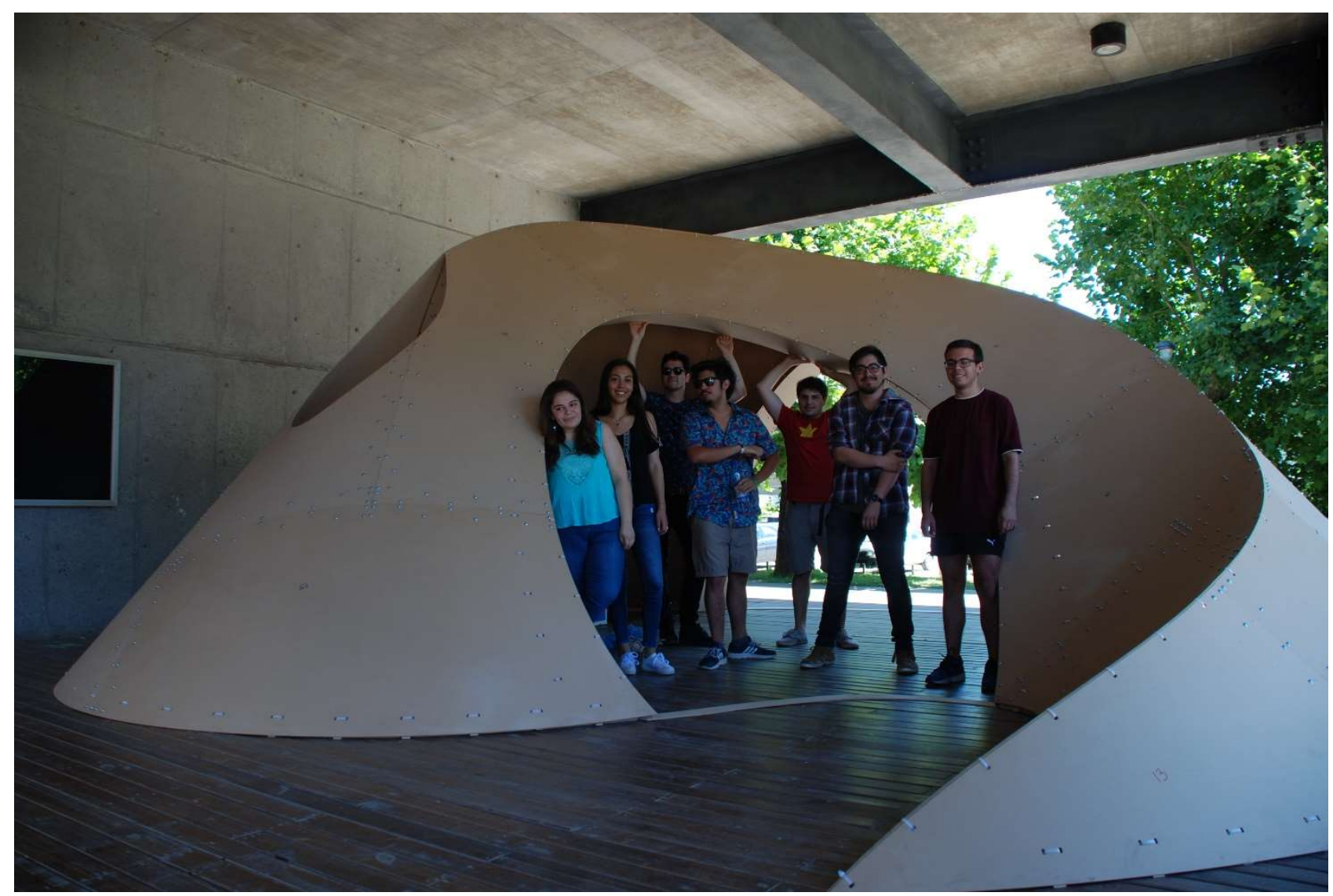

Fig. 10. Bio-Dune Pavilion, final phase (Source: Authors' own) 


\section{Results, constructability and lines of further improvement}

The theoretical and practical nature of the proposal and its vocation to be a complete exercise of digital construction, raises the obligation to specifically define the tools or machines (software, computers, cutting systems, etc.) for the control and production of an effective human-machine interface. From this theoretical reflection, it has become sufficiently clear that Fundamentals in Geometry provide the structure that is 'common' to these linguistic processes.

As a result, we have taken an experimental approach to the production of lightweight architecture in hightech and low-cost wood. This occurs within an academic context thanks to optimized cutting processes, and a sustainable production model with its own self-assembly system. Making the leap from the academic world to the industrial world means redefining several of these premises, and accepting a higher level of automation and rationalization.

In previous experiences and also in this participation, the assembly of the installation has required a large number of people due to the weight of the structure. It is possible to investigate the possibility of new materials that enable this type of difficulty to be reduced, such as employing recycled wooden products, wood foam and cork chipboard in an effort to reduce the density of the material.

It is important to study the curvature at each point in order to verify that there are no areas with a higher curvature than that which sheet of material can support. This is a direct contribution that digital technologies and parametric design can incorporate into the process. In the case of the Bio-Dune Pavilion, excessive curves can be seen in the vicinity of the end point of the crest. This led to an optimization of the design in accordance with strict geometric conditions, which involved the elimination of material by applying the curvature map of the surface.

\section{Conclusions}

Geometry is understood as knowledge prior to the use of parametric tools. With this knowledge, the condition of 'developability' of a surface has been understood and refined, and its morphological variants have thereby been explored. Low-cost wood laminars have been applied and subjected to variable efforts, which enable the space to be extensively covered with an ingenious execution. This experience therefore demonstrates new design paths for wood design and construction, which in turn open the door to new opportunities.

The Bio-dune pavilion experience held in Concepción, Chile, expresses an innovative application of biomimetic geometry for wood construction; it employs advanced design and manufacturing methods, and a major international collaboration in both research and teaching. In this context of digital manufacturing in wood, 'Geometry' appears as the conceptual support capable of giving a specific response to the requirements for the generation of the different forms of the project, their execution, and optimization. Not only does this system aim to optimize the use of material and structural efforts, but also to optimize the conception and production. Hence, inspired by the furniture industry, the combination of digital technologies and natural resources with modest local capacities not only provides a unique and significant product, but also presents an operational method that allows the generation of new architectural forms. 


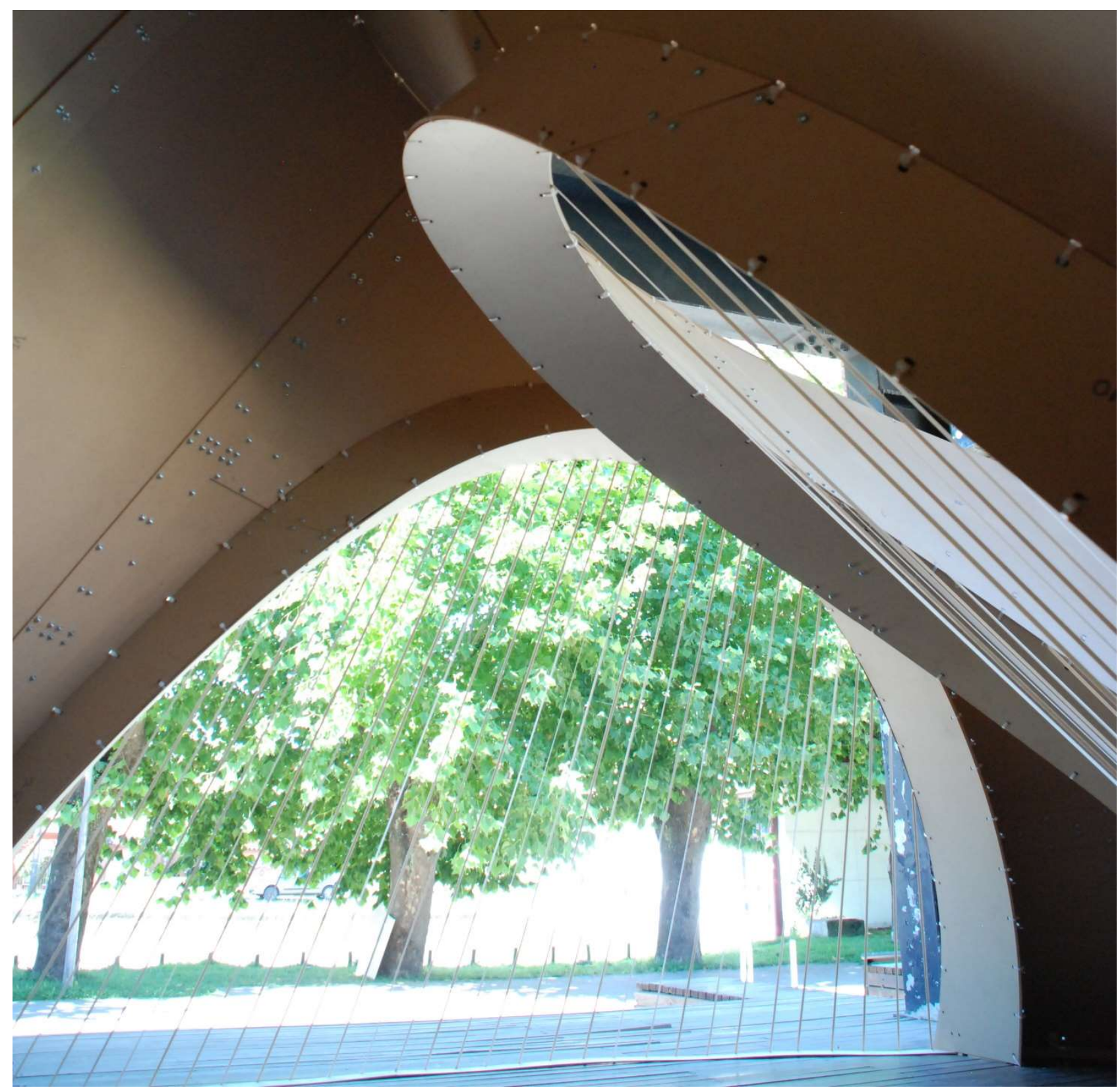

Fig. 11. Bio-Dune Pavilion, interior image and triangular access beam detail, with overlaps and fastening system using nylon flanges (Source: Authors' own) 


\section{REFERENCES}

Alvarado R G, Lagos R, Salcedo P, Ramos M, Labarca-Montoya C, Bruscato U (2009) Emociones precisas: fabricación digital en la enseñanza de la arquitectura; en Arquitetura Revista, Unisinos - Universidade do Vale do Rio dos Sinos, Vol. 5, n²:122-136.

Austern G, Guedi Capeluto I, Jacob Grobman Y (2018) Rationalization methods in computer aided fabrication: A critical review. Automation in Construction, 90: 281-293. https://doi.org/10.1016/j.autcon.2017.12.027

Barrallo, J et al (2017) Laminar Constructions and Reciprocal Structures. Nexus Netw J (2017) 19: 723.https://doi.org/10.1007/s00004-017-0346-8

Bohnenberger, Sascha, Rycke K, Weilandt A (2011) Lattice Spaces: Form optimisation throgh customization of non-developable 3d wood surfaces. In: 29th eCAADe Conference Proceedings, 751-758. eCAADe: Conferences. Ljubljana, Slovenia: University of Ljubljana. Faculty of Architecture.

Burry M (2013) From Descriptive Geometry to Smartgeometry. In: Peters B, Peters (eds) Inside Smartgeometry: Expanding the Architectural Possibilities of Computational Design. Wiley, Londres.

Casale A et al (2013) Surfaces: Concept, Design, Parametric Modeling and Prototyping. Nexus Netw J 15: 271.https://doi.org/10.1007/s00004-013-0146-8

Celani G (2012) Digital Fabrication Laboratories: Pedagogy and Impacts on Architectural Education. Nexus Netw J 14: 469. https://doi.org/10.1007/s00004-012-0120-x

Chiarella M, Martín-Pastor A (2015) Thinking Graphic and Design Collaborative. Developable geometries for folded architectural compositions, In: Proceedings of the XIX Conference of the Iberoamerican Society of Digital Graphics 2015, Blucher, São Paulo, p 702-707.https://doi.org/10.5151/despro-sigradi2015-110107

Chiarella M, Martín-Pastor A, Sáez N (2018) Graphic Thinking and Digital Processes: Three Built Case Studies of Digital Materiality. In: Castaño-Perea, E, Echeverria, E (eds) Architectural Draughtsmanship, From Analog to Digital Narratives. Springer, p 1033-1044. https://doi.org/10.1007/978-3-319-58856-8_81

Gentil Baldrich J M (1990) Método y aplicación de la Representación Acotada. Cuadernos EGA 2, Sevilla.

Glaeser G (2012) Geometry and its applications in arts, nature and technology. Springer, New York.

Glaeser G, Gruber, F (2007) Developable surfaces in contemporary architecture. Journal of Mathematics and the Arts, 1(1):59-71. https://doi.org/10.1080/17513470701230004

González-Quintial F et al (2013) Freeform Surfaces Adaptation through Developable Surfaces Using Apparent Contours. In: Zhang J., Sun C. (eds) Global Design and Local Materialization. CAAD Futures 2013. Communications in Computer and Information Science, vol 369. Springer, Berlin, Heidelberg.

Hauschild M, Karzel R (2011) Detail Practice: Digital Processes. Birkhäuser Architecture.

Hense M, Menges A, Weinstock M (2010) Emergent technologies and design: Toward a biological paradigm for architecture. Routledge, Oxon.

Iwamoto, L (2009) Digital Fabrications: Architectural and Material Techniques (Architecture Briefs). Princeton Architectural Press.

Izquierdo Asensi F (1985) Geometría Descriptiva Superior y Aplicada. Dossat.

Jabi W. Woodbury R (2013) Parametric Design Architecture, Laurence King, London. 
Kohler M, Gramazio F (2008) Digital Materiality in Architecture. Lars Müller Publishers.

La Gournerie, J M (1860-64) Traité de Géométrie descriptive. Mallet-Bachelier, Paris, [3 vols]

Martín-Pastor A (2015) Um retorno a os fundamentos da geometria. The Butterfly Gallery-Superfícies Helicoidais. Estratégias Geométricas para a Fabricação Digital. In: Cadernos PROARQ. Revista de Arquitetura e Urbanismo 25, UFRJ Post-graduation Program in Architecture, Rio de Janeiro, p 2-30.

Martín-Pastor A (2019) Augmented Graphic Thinking in Geometry. Developable Architectural Surfaces in Experimental Pavilions. In: Marcos C (ed) Graphic Imprints, Springer, p 1065-1075. https://doi.org/10.1007/978-3-319-93749-6_87

Martín-Pastor A, Torres-Holguín J, Narváez-Rodríguez R, Galindo-Díaz J (2014) Los workshops de geometría en Cad3D y prefabricación digital como estrategia docente en la enseñanza de la geometría para la arquitectura. Geometría y proyecto. In: Proceedings of the XVIII Conference of the Iberoamerican Society of Digital Graphics: Design in Freedom 2014, Blucher, São Paulo, p 213-216. https://doi.org/10.5151/desprosigradi2014-0040

Martín-Pastor A, Martín-Mariscal A, López-Martínez A (2017a) Rethinking Ephemeral Architecture. Advanced Geometry for Citizen-Managed Spaces. In: Mercader-Moyano, P (ed) Sustainable Development and Renovation in Architecture, Urbanism and Engineering, Springer, p 301-310. https://doi.org/10.1007/978-3319-51442-0_25

Martín-Pastor A, López-Martínez A (2017b) Helicoides desarrollables de hélice cilíndrica y su aplicación como superficie arquitectónica. In: Proceedings of Geometrías17, Coimbra, $16-18$ june 2017, p 73-77.

Meredith M (2008) From Control to Design. Parametric/Algorithmic Architecture. Actar, Barcelona.

Meredith N, Kotronis J (2013) Self-Detailing and Self-Documenting Systems for Wood Fabrication: The Burj Khalifa. In: Hesselgren L., Sharma S., Wallner J., Baldassini N., Bompas P., Raynaud J. (eds) Advances in Architectural Geometry 2012. Springer, Vienna.

Mesnil R, Douthe C, Baverel O, Léger B (2016) Marionette mesh: from Descriptive Geometry to FabricationAware Design, Advances in Architectural Geometry 2016, vdf Hochschulverlag AG, Zurich.http://dx.doi.org/10.3218/3778-4_7

Monge. G. (1769). Sur les développées des courbes à double courbure et leurs inflexions. Journal encyclopédique: $284-287$.

- 1780. Mémoire sur les propriétés de plusieurs genres de surfaces courbes, particulièrtement sur celles des surfaces d'eveloppables, avec une application à la theorie des ombres et des pénombres. Mémoires de divers sçavans 9, 9: 593-624 (written 1775)

- 1785. Mémoire sur les développées, les rayons de courbure, et les différents genres d'inflexions des courbes à double courbure. Mémoires de divers sçavans, 1, 10: 511-50 (written 1771)

- 1795a. Feuilles d'analyse appliquée à la géométrie. Paris. (Second ed. with the title e Applications de l'analyse à la géométrie. Paris: Baudouin, 1811)

- 1795b. Géométrie Descriptive. First ed. in e Les Séances des écoles normales recueillies par des sténographes et revues par des professeurs, Paris.

Narváez-Rodríguez R, Martín-Pastor A, Aguilar-Alejandre M (2014) The Caterpillar Gallery: Quadric Surface Theorems, Parametric Design and Digital Fabrication. In: Block P, Knippers J, Mitra N, Wang W (eds) Advances in Architectural Geometry 2014, Springer, pp. 309-322. https://doi.org/10.1007/978-3-319-114187_20 
Oxman R, Oxman R (2014) From Composition to generation. In: Theories of the digital in architecture. Routledge, New York.

Pottmann H (2010) Architectural Geometry as Design Knowledge. Archit Design, 80: 7277.https://doi.org/10.1002/ad.1109

Ramsgard Thomsen M, Tamke, M. (2013) Digital crafting: Performative thinking for material design. In: Peters B, Peters (eds) Inside Smartgeometry: Expanding the Architectural Possibilities of Computational Design. Wiley, London.

Sass L, Oxman R (2006) Materializing design: The implications of rapid prototyping in digital design. Design Studies, 27(3), 325-355.

Solomon J, Vouga E, Wardetzky M, Grinspun E (2012) Flexible developable surfaces. Comput Graph Forum 2012; 31:1567-76

Tafteberg Jakobsen I, Matthiasen J (2014) Descriptive Geometry and/or Computer Technology? What Mathematics is required for Doing and Understanding Architecture? Nexus Netw J (2014) 16: 505. https://doi.org/10.1007/s00004-014-0199-3

Weinstock M (2010) The Architecture of Emergence: The Evolution of Form in Nature and Civilisation. Wiley, Chichester.

Whitehead H (2005) Laws of form. In: B. Kolarevic (ed), Architecture in the Digital Age: Design and Manufacturing, Taylor \& Francis, New York.

\section{Acknowledgments}

CREDITS

BIO-DUNA PAVILION

Project and Design: Andrés Martín Pastor

Collaborator Design: Alicia López Martínez

Academic Coordination: Rodrigo García Alvarado

Manufacturing coordination: Alexis Pérez Fargallo. Manufacturing team: Prototype Laboratory, Escuela de Diseño Industrial, Fernando Figueroa Ramírez, Víctor Urrea Founet.

Assembly: Collaborative between teachers and students of the Workshop "Geometría y Fabricación Digital en Madera”: Andrés Vizcaíno, Juan Pablo Navarrete, Pablo Matus, Helmut Martes, Alex Hernández, Elvert Duran, Danitza Pereira, Francisca León Solís, Hugo Cáceres Bravo, Raúl Henriquez Reyex, Francisca Lavoz Fuenealba, Rodrigo Ceballos, Vicente Valenzuela. External collaborators: Stefánia Jara, Francisca Rozas.

Funding: Magister en Construcción en Madera, Doctorado en Arquitectura y Urbanismo, Centro de Investigación en Tecnologías de la Construcción (CITECUBB), Asociación Universitaria Iberoamericana de Postgrado. AUIP

Collaborations and acknowledgments: Cecilia Poblete Arredondo (UBB). Ricardo Hempel Holzafphel (UBB). Víctor Mora Padrón (HUBiobio). Ariel Bobadilla Moreno (CITECUBB). Verónica Otarola Sanzana (UBB). Carlos Campos Saez (UBB). Pamela Sierra Villalobos (UBB). Pedro Concha Márquez (CITECUBB). Department of Graphic Engineering, Universidad de Sevilla. Escuela Técnica Superior de Ingeniería de la Edificación, ETSIE, Sevilla. Research group "HUM976: Expregráfica. Lugar, Arquitectura y Dibujo". Instituto Universitario de Arquitectura y Ciencias de la Construcción (IUACC. Universidad de Sevilla). Research group "Arquitectura y Construcción Sustentable. GACS-UBB". 


\section{PREVIOUS WORK CREDITS}

\section{The Caterpillar Gallery}

Project and Design: Roberto Narváez-Rodríguez, Andrés Martín-Pastor In collaboration: Margarita Infante-Pereda, María Aguilar-Alejandre Manufacture: Fablab Sevilla Assembly: Teachers and students of ETSIE and ETSA, Universidad de Sevilla Collaboration: Department of Graphic Engineering, ETSIE, Universidad de Sevilla

\section{The Coccon Gallery}

Project and Design: Andrés Martín-Pastor, Roberto Narváez-Rodríguez Manufacture: Fablab UNAL Medellín team Execution and Assembly: students of UNAL Medellín and UNAL Manizales Coordination: Facultad de Arquitectura. Unal Medellín, Colombia

Collaboration: Department of Graphic Engineering, ETSIE, Universidad de Sevilla

\section{SSFS Pavilion - Santa Fe}

Project and Design: Andrés Martín-Pastor, Roberto Narváez-Rodríguez Parametric co-design: Juan Expósito Bejarano

Academic Coordination and management: Mauro Chiarella

Programa Maestría en Arquitectura, FADU, Universidad Nacional del Litoral, Argentina Manufacture and Assembly: Teachers and students of FADU

Collaboration: Department of Graphic Engineering, ETSIE, Universidad de Sevilla

The Butterfly Gallery

Project and Design: Andrés Martín-Pastor, Juan Expósito Bejarano

Academic Coordination: María Angela Dias. Programa de Pós-graduação em Arquitetura, FAU,

Universidade Federal do Rio de Janeiro (UFRJ), Brasil

Manufacture: LAMO3D, Foco Design

Assembly: Teachers and students of UFRJ

Collaboration: Department of Graphic Engineering, Universidad de Sevilla, ETSIE, Fablab Sevilla

\section{SSFS Pavilion - Fablab Sevilla}

Project and Design: Andrés Martín-Pastor, Juan Expósito Bejarano y Roberto Narváez Rodríguez Manufacture: Fablab Sevilla

Production Manager: Daniel del Valle. Safety director: Alejandro Flores Pina

Assembly: Teachers and students of ETSIE, ETSA and Edificalab

Collaboration: European Researchers' Night, Department of Graphic Engineering, Universidad de Sevilla, ETSIE

\section{Molusco - Pavilion}

Project and Design: Andrés Martín-Pastor, Alicia López Martínez

Academic Coordination: Antonio Olmos and Johanna Ebrahaim. Fablab Uninorte. Universidad del Norte, Barranquilla, Colombia.

Manufacture: Fablab UNAL Medellín. Universidad Nacional de Colombia, sede Medellín.

Manufacturing team: Edgar Alonso Meneses, Juan Pablo Gutiérrez, Luis Daniel Asprilla, Camilo Andrés Idárraga

Assembly: Teachers and students of Universidad del Norte, Colombia.

Collaboration: Department of Graphic Engineering, ETSIE, Universidad de Sevilla, Fablab Sevilla 


\section{CAPTION}

Fig.1: Bio-Dune Pavilion. Hilario Hernández Gurruchaga Library, Bío-Bío University, Concepción, Chile, January 2017

Fig.2a: Caterpillar Gallery, Seville 2014; Fig.2b: Cocoon Gallery, Medellin 2014; Fig.2c: SSFS Pavilion Santa Fe, 2015; Fig.2d: Butterfly Gallery, Rio de Janeiro 2015; Fig.2e: SSFS Pavilion - Fablab Sevilla, 2015; Fig.2f: Molusco-Pavilion, Barranquilla 2016; Fig. 2g: Dieste-Pavilion, Montevideo 2017

Fig. 3. This diagram summarizes the three main phases of the process: Design, Manufacture, and Assembly, showing the lines of feedback that occur between said phases (Source: Authors' own).

Fig. 4. Assembly manual of the Bio-Dune Pavilion. (Source: Authors' own)

Fig. 5. Assembly of the model reduced to a scale of 1:8, and where to check for possible errors and to optimize processes (Source: Authors' own)

Fig. 6. The dune is generated as the enveloping surface of a series of cones of the same slope (Source: Authors' own)

Fig. 7. Reorganization on site. Bio-Dune Pavilion (Source: Authors' own)

Fig. 8. Assembly of the Bio-Dune Pavilion as a single skin (Source: Authors' own)

Fig. 9. Curvature and fastening of the skin along the crest of the dune and along the base beam (Source: Authors' own)

Fig. 10. Bio-Dune Pavilion, final phase (Source: Authors' own)

Fig. 11. Bio-Dune Pavilion, interior image and triangular access beam detail, with overlaps and fastening system using nylon flanges (Source: Authors' own) 